\title{
What is "Normative" at Cooling Water Intakes? Defining Normalcy Before Judging Adverse
}

\author{
Charles C. Coutant \\ Environmental Sciences Division \\ Oak Ridge National Laboratory ${ }^{1}$ \\ Oak Ridge, TN 37831-6036 \\ E-mail: coutantcc@ornl.gov
}

\begin{abstract}
Judgments of adverse environmental impact from cooling water intake structures need to be preceded by an appreciation of what is normal. In its report, Return to the River, the Independent Scientific Group (now called the Independent Scientific Advisory Board)--the scientific peer review arm of the Northwest Power Planning Council-advanced the notion of a "normative river ecosystem" as a new conceptual foundation for salmonid recovery in the Columbia River basin. With this perspective, the sum of the best scientific understanding of how organisms and aquatic ecosystems function should be the norm or standard of measure for how we judge the effects of human activities on aquatic systems. For the best likelihood of recovery, key aspects of altered systems should be brought back toward normative (although not necessarily fully back to the historical or pristine state); new alterations should be judged for adversity by how much they move key attributes away from normative or what might be considered normal. In this presentation, I ask what "normative" is for the setting of cooling water intake structures and how this concept could help resolve long-standing disputes between groups interested in avoiding damage to all organisms that might be entrained or impinged and those who take a more population or community perspective for judging adverse environmental impact. In essence, I suggest that if a water intake does not move the aquatic ecosystem outside the "normative" range, based on expressions of normalcy such as those discussed, then no adverse impact has occurred. Having an explicit baseline in normal or normative would place $316(\mathrm{~b})$ analyses on the same conceptual foundation as 316(a) analyses, which strive to demonstrate the continuation of a balanced, indigenous community of aquatic organisms at the power station location.
\end{abstract}

\footnotetext{
${ }^{1}$ Oak Ridge National Laboratory is operated for the U.S. Department of Energy under contract DE-AC05960R22464 with Lockheed Martin Energy Research Corp.
} 


\section{DISCLAIMER}

This report was prepared as an account of work sponsored by an agency of the United States Government. Neither the United States Government nor any agency thereof, nor any of their employees, make any warranty, express or implied, or assumes any legal liability or responsibility for the accuracy, completeness, or usefulness of any information, apparatus, product, or process disclosed, or represents that its use would not infringe privately owned rights. Reference herein to any specific commercial product, process, or service by trade name, trademark, manufacturer, or otherwise does not necessarily constitute or imply its endorsement, recommendation, or favoring by the United States Government or any agency thereof. The views and opinions of authors expressed herein do not necessarily state or reflect those of the United States Government or any agency thereof. 


\section{DISCLAIMER}

Portions of this document may be illegible in electronic image products. Images are produced from the best available original document. 


\section{Introduction}

The community of regulators, managers, and analysts concerned with the Clean Water Act Section 316(b) is perplexed over defining and assessing "adverse environmental impact." Under the law, operators of steam electric station cooling water intake structures must use the best technologies available to minimize adverse environmental impact, although what constitutes an adverse impact is not defined. In contrast, the sibling statute, 316(a), which addresses thermal discharges, sets a standard of normalcy for judging harm by including the requirement for protection of a "balanced indigenous population" (generally and legally interpreted as a balanced ecological community of mostly native species). For analogous consideration of 316(a) and 316(b), especially for the same power station, it seems logical to consider what is normal in the vicinity of cooling-water intakes before making a judgment of what is an adverse effect.

Site specificity of $316(\mathrm{~b})$ concerns seems to have overridden any consideration of commonality (or normal) for the physical setting and biological processes near water intakes. There are obviously common engineering criteria for intake locations and designs that fulfill the needs of plant operations. These criteria have been modified over the years with general site selection criteria for minimizing biological effects of entrainment and impingement (locating intakes flush with shorelines rather than indented, using deep water rather than surface water, etc.) and certain intake designs have been recommended that have shown fewest biological losses (e.g., Majewski and Miller 1979; IAEA 1980). A valuable series of conferences on entrainment and impingement in the 1970s helped focus concerns and identify solutions. Yet despite these efforts, there emerged no clear view of what is normally expected for an ecological community at a cooling-water intake as a comparison for effects that might be judged adverse. Such a perspective is needed in order to decide whether existing "best available technologies" are adequate, or whether additional improvements must be made.

A useful example for the application of normal as a basis for judging adverse may be found in salmon recovery efforts in the Pacific Northwest. In its report, Return to the River, the Independent Scientific Group (ISG; now called the Independent Scientific Advisory Board)--the scientific peer review arm of the Northwest Power Planning Council-advanced the notion of a "normative river ecosystem" as a new conceptual foundation for salmonid recovery in the Columbia River basin (ISG 1996). It specifically addresses the need for a baseline for judging the benefit or detriment of change. With this perspective, the sum of the best scientific understanding of how organisms and aquatic ecosystems function should be the norm or standard of measure (= "normative") for how we judge the effects of human activities on aquatic systems. Alterations to an aquatic system should be 
judged for adversity by how much they move the community composition and key functions away from normative or what might be considered normal. For the best likelihood of ecosystem recovery for salmon, the ISG recommended that key aspects of altered salmonid ecosystems should be brought back toward normative for the species and supportive biotic community (although not necessarily fully back to the historical or pristine conditions; how far the return must go to restore needed functions depends on the specific situation).

In this presentation, I ask us to think about what "normative" is for the environmental setting of cooling water intake structures and how this concept could help resolve long-standing disputes between groups interested in avoiding damage to all * organisms that might be entrained or impinged and those who take a more population or community perspective for judging adverse environmental impact. It is a concept for how we think through our analysis of what is adverse at a site rather than a prescriptive definition. I suggest that the concept can be useful for not only helping to define adverse, but for better understanding the effects of cooling water intake structures, selecting species or metrics for analysis, designing studies to characterize and quantify effects, and selecting the most appropriate technologies for minimizing adverse environmental impacts.

A few of the normative features that have bearing on the possible design or siting of intake structures are described below (Figure 1). I encourage further discussion and elaboration.

\section{Abundant Water}

Cooling-water intakes for once-through thermal electric power stations need to be located on fairly large bodies of water or rivers with large flows, a requirement that has implications for other normative features. Heat dissipation from a power station requires both large volumes of water and a large heat dissipation area. Small waterbodies would cause recirculation of heated water into the intakes, a phenomenon that is energetically inefficient for power generation. Thus, the normative situation begins with a fairly large lake, river or estuary (occasionally an open coast). This temperature-driven requirement sets certain spatial characteristics of the zone of influence for cooling-water intakes--the zone will be large. Large geographic extent generally means that source populations of organisms that could be impinged or entrained will be large or at least geographically widely dispersed. It also means that finding a suitable reference site for the classical approach of site comparisons for monitoring impacts will be difficult (what is easy on a stream reach affected by an industrial discharge is not easy when one must find a reference site for a large lake or estuary)... 


\section{Pronounced Circulation}

Thermal discharges need to be dissipated widely to the environment. Even in large bodies of water, there should be sufficient circulation of effluent away from the vicinity of the power station to avoid recirculation into the intake. Thus, waters near intakes generally have distinct along-shore currents (lakes), tides (estuaries and coastal waters) or unidirectional flows (rivers). At some power stations, the physical setting includes explicit use of water withdrawn from deep strata that are cool in summer, with thermal discharge to surface waters where there is heat transfer to the atmosphere. This separation of flow is often accomplished with skimmer walls or other designs to provide deep intake water. Thus, circulation needs to be considered in the vertical plane as well as horizontal. Having large circulation rates also implies large geographic extent for affected biota. The actual extent may be difficult to establish with an accuracy needed for quantitative assessments of power station impacts.

High natural circulation rates in a waterbody suggest that there will be species of organisms there that are adapted to use this circulation in their life-cycle strategies.

Currents are used by attached organisms as a food-delivery mechanism. They are used by other species as a dispersal mechanism. Inhabitants of estuarine ecosystems have evolved to use tidal currents for dispersal of early life stages, with life-cycle strategies of different species involving spawning at all possible locations inside and outside the estuary and early-life-history stage strategies of movement into or out of the estuary with tides.

\section{Biota are Not Uniformly Distributed}

Even the most passive, planktonic organisms are not uniformly distributed in a waterbody. In the vicinity of intakes, there will be patchiness due to circulation patterns (an aerial view of a lake rich in plankton or silt will nearly always reveal huge swirls and eddies of varying density and color). Organisms have preferences for depth and distance from shore. Mobile and stationary organisms tend to occur in groups (schools of moving fish or patches of benthic organisms). Organisms come and go in the vicinity of intakes depending on hour of day and time of year. Such characteristics are often species specific, and good generalizations can be made regarding a site by simply knowing the species composition. Details, however, are site-specific and must be confirmed by on-site studies. The actual zone of water withdrawal needs to be known. These distribution patterns of both biota and the entrained water offer opportunities to select intake location and design to avoid interactions with valued biota. They also mean that models designed to estimate the 
numbers of organisms entrained or impinged must be cognizant of the actual distribution patterns in space and time in the source water if they are to be reasonably realistic.

\section{Intake Flows Will Seem 'Natural' to Biota}

When high rates of circulation are the norm in a waterbody, it is likely that organisms in it will respond to intake flows as extensions of natural current patterns. Attached bottom organisms that colonize flowing waters can be expected to colonize the bottoms and walls of intakes. More importantly for $316(\mathrm{~b})$ issues, drifting organisms can be expected to follow the induced flows into the intake. Species and life stages that specifically use natural currents as dispersal mechanisms, e.g., planktonic larvae, can be expected to not only drift passively with the inflowing water, but to select it if they have such an ability. It is common for estuarine organisms, especially, to use tidal currents to enhance their ability to move about (some will rise in the water column on incoming tides, for instance, when they seek to move to the head of an estuary, and sink to the bottom to maintain position during ebb tides). There is some indication that organisms suspended in a watermass with no cues to location (not being able to sense the bottom or shore) will obtain directional cues from turbulent vortices. Turbulence structure in an intake may enhance the perception of that route as being the "right way to go." Although behavioral barriers have been explored at intakes, there seems to have been little attempt to guide organisms away from intakes by using knowledge of their current-following behavior.

\section{Current Dispersal $=$ Large Numbers $=$ High Natural Mortality Rate}

Organisms with a life-history strategy of dispersing early life stages in currents generally do so in high numbers. This is a bad news-good news story for power station intakes. This strategy usually translates to large numbers being entrained (or impinged, if large enough). This is the bad news (counts of entrained larvae or impinged juvenile fish can sound astronomically high and clearly agitate those people concerned most with losses of individuals). The dispersal strategy also translates to a normal expectance of high mortality rates. This is the good news (losses of entrained or impinged organisms, when they occur, may easily be a small part of the normal high mortality rate). An analysis to establish adverse impact is thus most appropriately directed at determining whether there is a population effect of this added mortality, not on the fact of large numbers of organisms entrained or impinged. This is the logic behind the modeling efforts discussed in the workshop. 


\section{Natural Die-offs}

It is also quite normal for certain populations of organisms to undergo massive dieoffs, often as a result of natural phenomena. Because cooling-water intakes draw these moribund or dead individuals into the intake, the power station is often unjustifiably pinpointed as the cause. For example, gizzard shad in northern latitudes of the U.S. and threadfin shad in more southern latitudes are highly susceptible to cold (McLean et al. 1980). Sudden autumn weather fronts or progressive winter cooling in a cold year will cause these fish to become lethargic and often die in great numbers. The fish, however, have a high capacity for recovery of populations (McLean et al. 1982). Episodes of high impingement "mortalities" under these circumstances are thus quite normal for both the population and ecosystem. The greatest problem may not be ecological but for the power station operators in dealing with the massive influx of bodies.

\section{High Natural Mortality Rate $=$ Compensatory Mechanisms}

Species that broadcast early life stages to currents or experience periodic die-offs "anticipate" large losses and generally have well-developed mechanisms for compensating for highly variable survival in the face of environmental vagaries. Compensation in such species is not an abnormal response to human-induced changes but a very normative part of their evolved life-cycle strategy. To the extent that these compensatory mechanisms are not exceeded by the sum of all mortality (power station and other), an observed loss of organisms followed by compensation is a very normal part of a species' existence. The key for the analyst, of course, is to distinguish when that compensatory ability starts to be exceeded.

For some populations, the word "compensation" has the wrong connotation. The word implies an adjustment made to overcome some previous adverse effect. In fact, loss of many individuals from a population may be a necessary part of allowing the remaining ones to attain their full potential. In black basses, for example, cohorts that retain a large percentage of their individuals as the juveniles grow experience nearly uniform, slow growth rates and few overall survivors. On the other hand, cohorts that quickly show a few large individuals and rapid losses of most others will persist as a dominant year-class (DeAngelis and Coutant 1979). A reasonable amount of culling of early life stages, with return of the biomass to the ecosystem (as food for others), is not just normal but probably necessary.

\section{Others?}


Clearly, there are other features that one could consider normative for the vicinities of cooling-water intakes. My intent is not to catalog all of them, but to stimulate an approach to thinking about adversity that is not generally taken. Even as we delve into the specificity of a site, we can still obtain perspective on what is adverse there if we first ask what is normal in the context of the aquatic system and its biotic components.

\section{Balanced Indigenous Community}

The baseline mandated for 316(a) analyses seems inherently applicable to 316(b), also. The combination of effects from a power station--thermal, entrainment, impingement, chemical, etc.--will either change the community in ways detrimental for human values or it will not. From the perspective of seeking the normative condition, however, we must question whether any biotic community in a large water body is ever "balanced" in the true sense. Populations always fluctuate in response to natural phenomena. Community structure rarely remains static. That variability over time is clearly the normal condition. Nonetheless, we can use this normally variable condition as a guide to predicting or monitoring major trends in species abundance that we would consider either normal or adverse.

\section{Adverse on a Scale Between Normative and Disturbed}

We can view an effect of an intake as adverse if it tends to move the aquatic system from a condition of normalcy (normative) toward one that is disturbed or "unbalanced" (Figure 1). Normative, as the norm or standard of measure, has a range of variation (solid arrow) that we can define with adequate monitoring and understanding of the species and ecosystem. Some effects of an intake will not alter the normal range. Effects that extend this variability "too much" toward the disturbed condition would be considered adverse. Our view of adverse, however, can be affected by social decisions (the dashed alternatives $a$ and $b$ in Figure 1). In our natural-cultural systems, we may willingly compromise some features of aquatic systems for other uses, such as a reduced population size of a managed game species in order to allow for multiple uses of the watershed. Deciding where on this scale change becomes adverse is not easy, but it is immensely more difficult if there is no understanding of what is normative.

\section{Conclusion}

Although the withdrawal of large amounts of water for power plant cooling entails many site-specific considerations, there are also many features that are typical of all sites and can be considered normal or normative. Overemphasis on site specificity ensures that 
old arguments about adverse impacts need to be made time and again. It seems appropriate to consider a different approach.

An alternative approach is to carefully evaluate what is normal or expected in the vicinity of such an intake based on knowledge of ecosystems and other intakes at similar locations. Adversity can then be evaluated against this baseline. Common occurrences that are not adverse can be recognized as such and not cause alarm. Typical, normative features can be used as guides for site selection, intake design, and potential modifications to lessen adverse impacts. Considerations of ecosystem normalcy inevitably lead to a broad perspective of population and community evaluation rather than emphasis on losses of individual organisms. In essence, if an intake structure does not move the aquatic ecosystem outside the "normative" range, based on expressions of normalcy such as those suggested above, then no adverse impact has occurred. This perspective places 316(b) analyses in the same conceptual framework as 316(a) analyses, which strive to demonstrate the continuation of a balanced, indigenous community of aquatic organisms at the power station location.

\section{References}

DeAngelis, D. L., and C. C. Coutant. 1979. Growth rates and size distributions of firstyear smallmouth bass populations: Some conclusions from experiments and a model. Transactions ofa he American Fisheries Society 108:137-141.

IAEA (International Atomic Energy Agency). 1980. Environmental Effects of Cooling Systems. Technical Reports Series No. 202. Vienna, Austria.

ISG (Independent Scientific Group). 1996. Return to the River. Restoration of Salmonid Fishes in the Columbia River Ecosystem. Prepublication Review Draft. Northwest Power Planning Council, Portland, Oregon.

Majewski, W., and D. C. Miller. 1979. Predicting effects of power plant once-through cooling on aquatic systems. Technical Papers in Hydrology 20. UNESCO, Paris.

McLean, R. B., P. T. Singley, J. S. Griffith, and M. V. McGee. 1980. Threadfin shad impingement: Effect of copld stress. ORNL/NUREG/TM-340. Oak ridge National Laboratory, Oak Ridge, Tennessee. 
McLean, R. B., P. T. Singley, D. M. Lodge, and R. A. Wallace. 1982. Synchronous spawning of threadfin shad. Copeia 1982:952-955.

Figure 1. A conceptual scale between normative and disturbed aquatic systems. Normative is a range of conditions which we might consider normal, based on best scientific understanding. Effects of power-station intakes can move conditions within the normative range (effects 1and.2; acceptable) or outside it (effects 3 and 4; adverse). However, the degree to which change is acceptable depends on social decisions, noted by adverse $a$ and adverse $b$. 

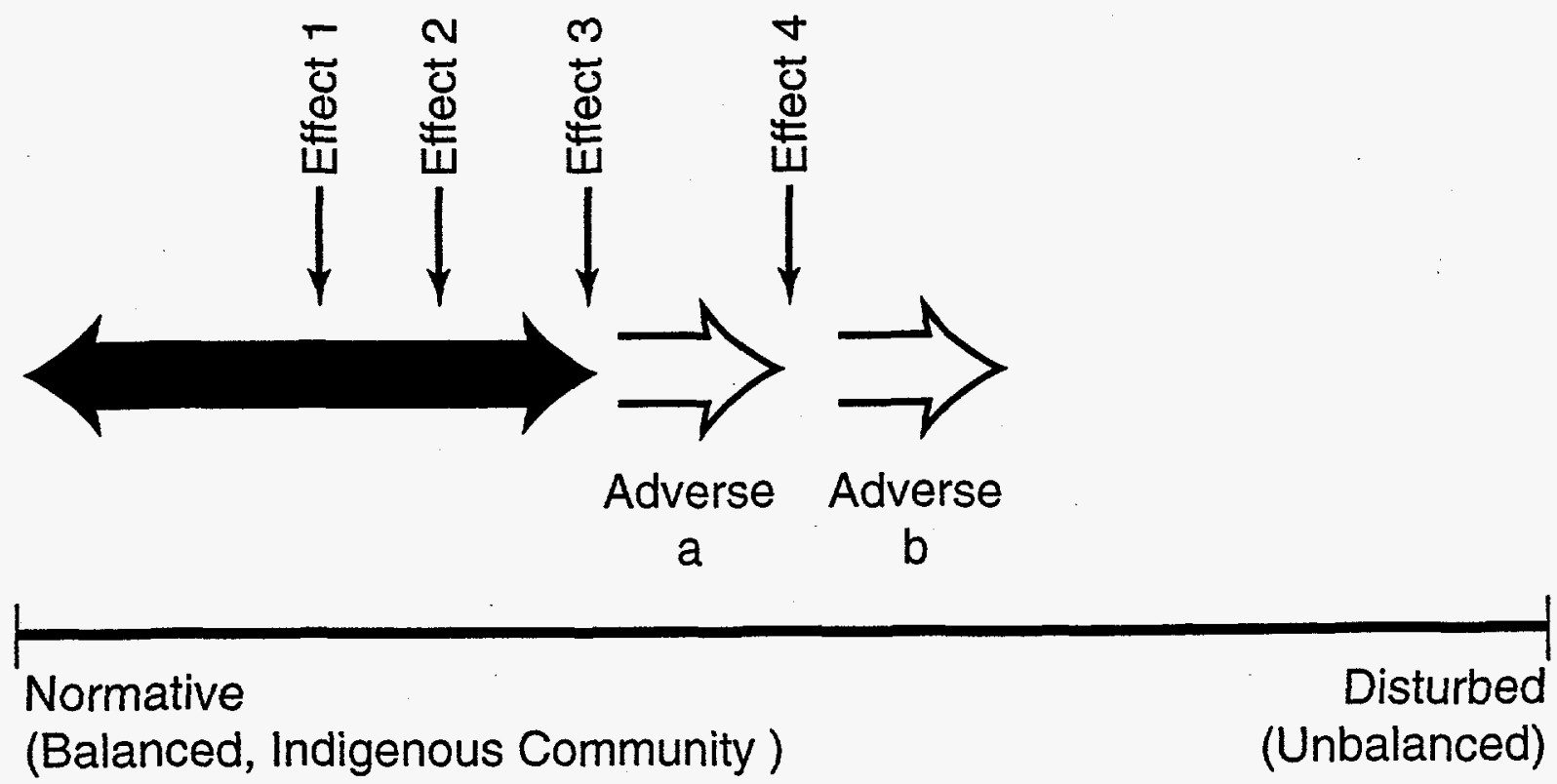